\title{
Endoscopic percutaneous drainage in a COVID-19 patient with iatrogenic gastric perforation
}

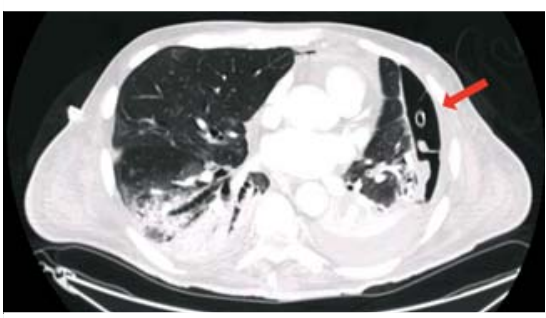

- Fig. 1 Computed tomography scan of the thorax showing SARS-CoV-2-related pneumonia and left pulmonary drainage (red arrow).

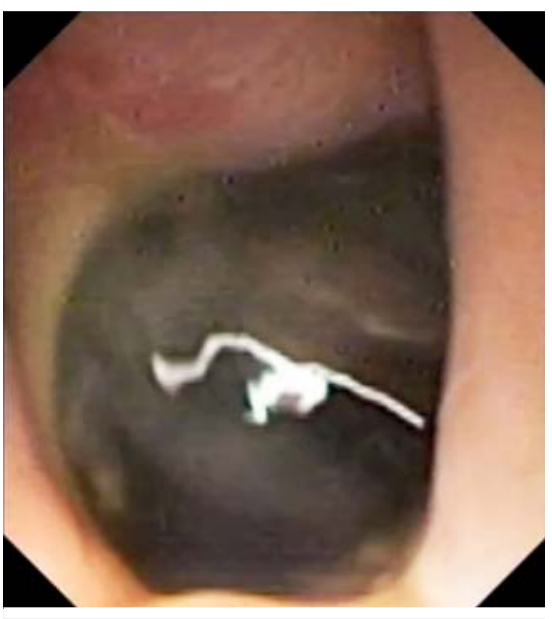

- Fig. 2 Endoscopic view of gastric perforation in the fundus of the stomach.

A 60-year-old male under mechanical ventilation through endotracheal intubation due to severe COVID-19 pneumonia was treated at our intensive care unit (ICU) with extracorporeal membrane oxygenation for several weeks. Computed tomography (CT) revealed bilateral lung involvement and a left pulmonary abscess drained by a percutaneous catheter (> Fig.1). Percutaneous endoscopic gastrostomy (PEG) was performed, but the patient developed an early buried bumper syndrome [1-4] after one month, so the tube was removed and gastroscopy showed an unexpected gastric perforation of the fundus ( $>$ Fig. 2 , $>$ Video 1 ), defined as de novo perforation.
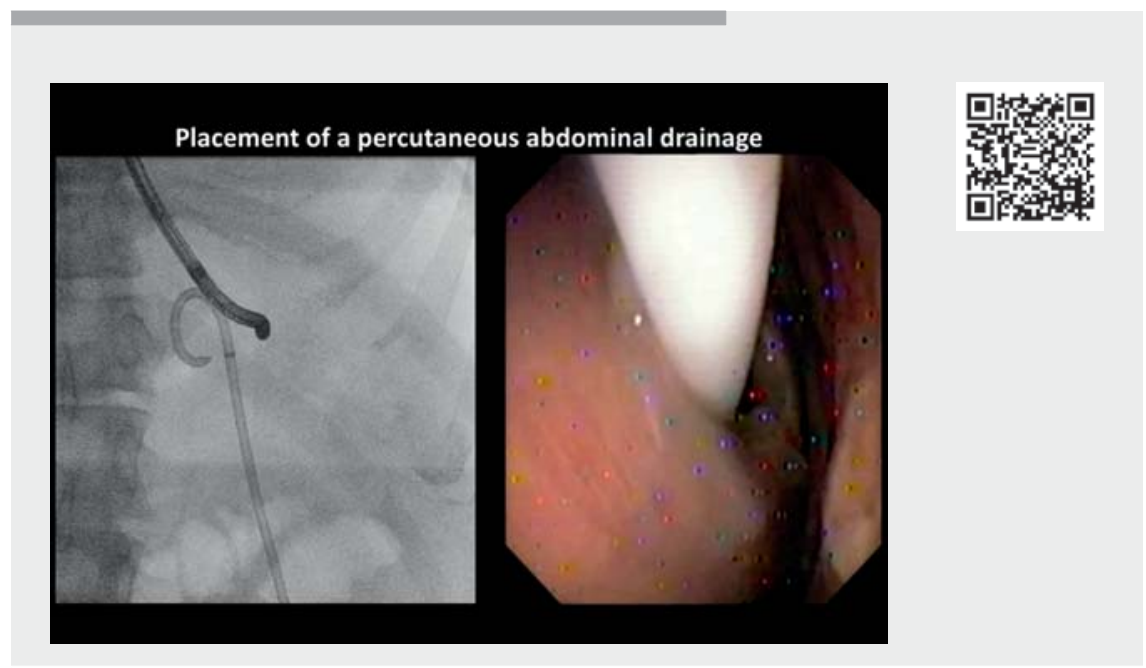

Video 1 Video shows how the percutaneous intra-abdominal drainage was inserted through the patient's abdominal wall defect under direct endoscopic and radiologic visualization. Later, a full-thickness continuous suture was successfully performed using the OverStitch suturing device.

A CT scan showed a fluid collection in the left upper abdominal region, so the multi-disciplinary decision was to perform a peritoneoscopy (with a 6-mm scope), which was safely performed thanks to the insufflation of carbon dioxide [5]. The ultra-slim scope allowed us to cross the gastric leak and directly visualize the diaphragm ( Fig.3a),

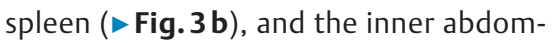
inal wall defect from PEG insertion ( Fig. 3c).

The patient was critically ill and unfit for surgery, so we placed a percutaneous drainage and closed the leak with an endoscopic suturing system. The isolated COVID-ICU room was organized as an endoscopic theater, allowing us to perform the procedure at bedside. The percutaneous drainage was inserted through the abdominal wall defect (previous PEG fistula) under direct endoscopic and radiologic visualization (> Fig.4a,b). Continuous sutures were performed using the OverStitch suturing device (Apollo Endosurgery, Inc., Austin, Texas, USA)
( Video 1), and closure was confirmed by the absence of intra-abdominal contrast diffusion after intra-gastric contrast injection ( $\triangleright$ Fig.5).

Meanwhile, the SARS-CoV-2 infection resolved, allowing his transfer to the ICU, where a second gastroscopy was necessary due to lack of clinical improvement. It showed another leak next to the sutured area, so another suture was performed and strengthened with a whipstitch over it ( Video 1 ). The absence of intra-abdominal contrast diffusion confirmed the complete closure, but he died one month later from his terminal pulmonary condition.

Endoscopy_UCTN_Code_TTT_1AO_2AI

Competing interests

The authors declare that they have no conflict of interest. 

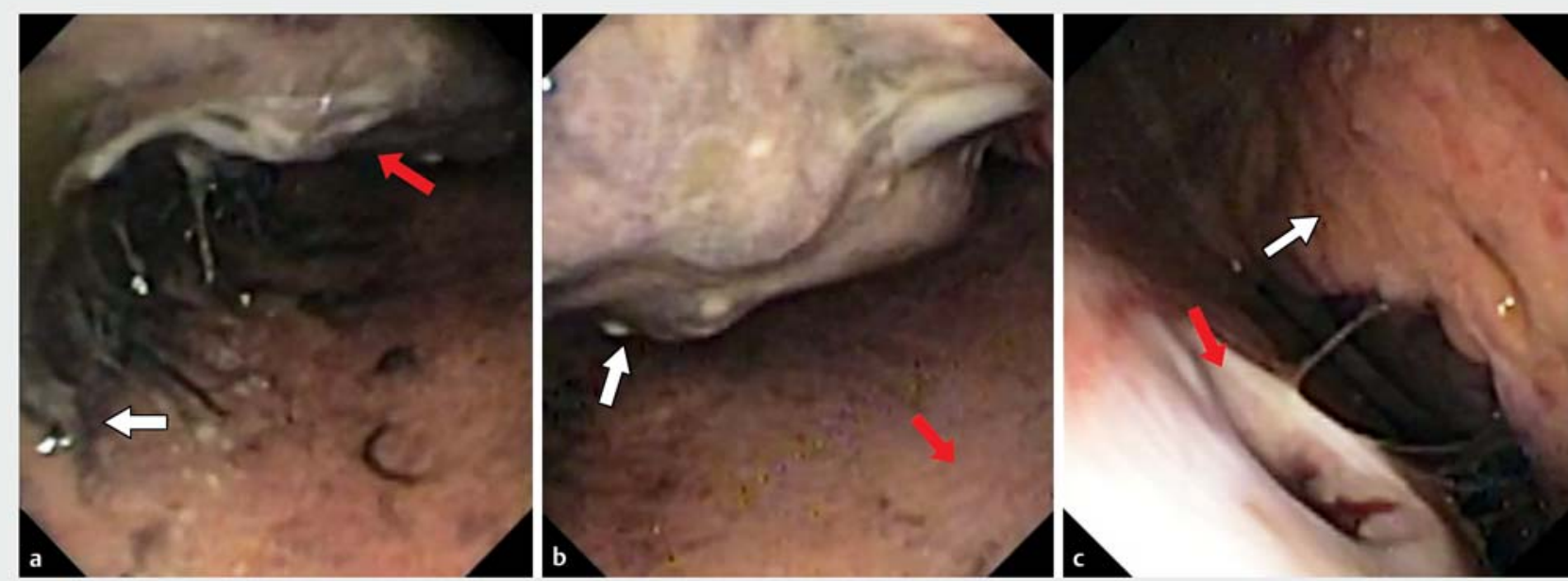

- Fig. 3 Endoscopic view of intra-abdominal cavity showing abdominal organs. a Diaphragm (white arrow) on the left side and spleen at the top (red arrow). b Spleen (white arrow) and inner abdominal wall (red arrow). c Previous percutaneous endoscopic gastrostomy fistula (red arrow) and omentum (white arrow).
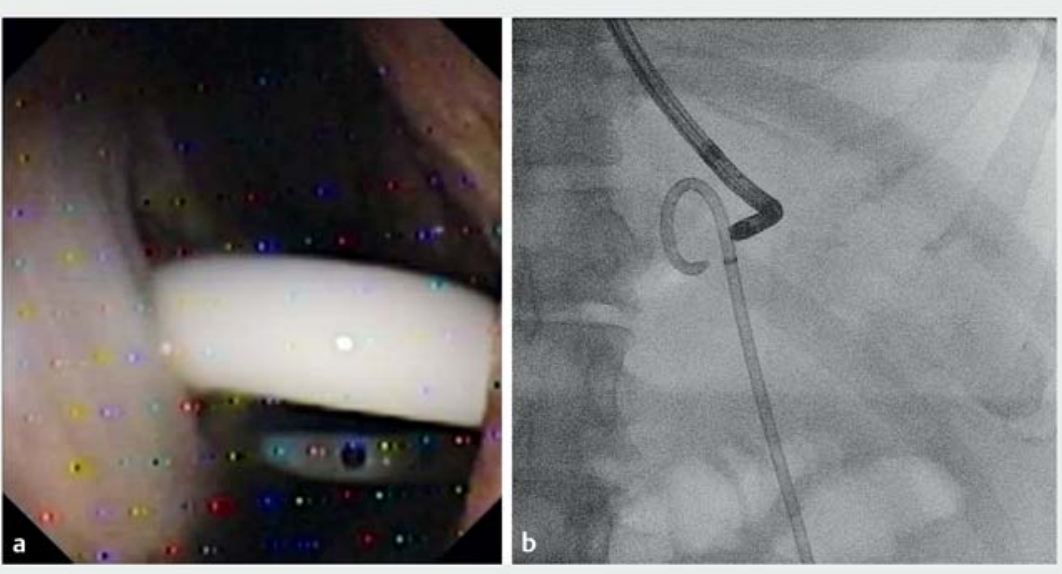

Fig. 4 Pigtail catheter insertion. a Endoscopic view. b Radiographic view.

The authors

Antonino Granata ${ }^{1} \odot$, Gennaro Martucci ${ }^{2}{ }^{\odot}$ Giacomo Emanuele Maria Rizzo ${ }^{1,3,4}$, Dario Ligresti ${ }^{1}{ }^{\oplus}$, Antonio Arcadipane ${ }^{2}$, Mario Traina

1 Endoscopy Service, Department of

Diagnostic and Therapeutic Services, IRCCSISMETT, Palermo, Italy

2 Department of Anesthesia and Intensive Care, IRCCS-ISMETT, Palermo, Italy

3 Section of Gastroenterology \& Hepatology, Department of Health Promotion Sciences Maternal and Infant Care, Internal Medicine and Medical Specialties, PROMISE, University of Palermo, Palermo, Italy

4 Department of Surgical, Oncological and Oral Sciences (Di.Chir.On.S.), University of Palermo, Palermo, Italy
Corresponding author

\section{Antonino Granata, MD}

Endoscopy Service, Department of

Diagnostic and Therapeutic Services,

IRCCS-ISMETT, Via Ernesto Tricomi, 5,

90126 Palermo, Italy

agranata@ismett.edu

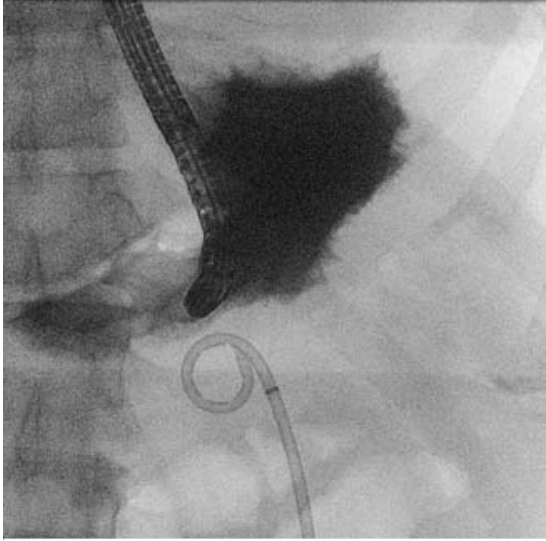

Fig. 5 No leak was found with injection of intra-gastric contrast on radiography.

\section{References}

[1] Arvanitakis M, Gkolfakis P, Despott EJ et al. Endoscopic management of enteral tubes in adult patients - Part 1: Definitions and indications. European Society of Gastrointestinal Endoscopy (ESGE) Guideline. Endoscopy 2021; 53: 81-92. doi:10.1055/a-1303-7449

[2] Gkolfakis P, Arvanitakis M, Despott EJ et al. Endoscopic management of enteral tubes in adult patients - Part 2: Peri- and post-procedural management. European Society of Gastrointestinal Endoscopy (ESGE) Guideline. Endoscopy 2021; 53: 178-195. doi:10.1055/a-1331-8080 
[3] Anderloni A, Di Leo M, Barzaghi F et al. Complications and early mortality in percutaneous endoscopic gastrostomy placement in Lombardy: a multicenter prospective cohort study. Dig Liver Dis 2019; 51: $1380-$ 1387

[4] Pih GY, Na HK, Ahn JY et al. Risk factors for complications and mortality of percutaneous endoscopic gastrostomy insertion. BMC Gastroenterol 2018; 18: 101

[5] Lo SK, Fujii-Lau LL, Enestvedt BK et al. The use of carbon dioxide in gastrointestinal endoscopy. Gastrointest Endosc 2016; 83: 857-865
Bibliography

Endoscopy 2022; 54: E686-E688

DOI 10.1055/a-1750-8990

ISSN 0013-726X

published online 18.2.2022

(C) 2022. Thieme. All rights reserved.

Georg Thieme Verlag KG, Rüdigerstraße 14,

70469 Stuttgart, Germany

\section{ENDOSCOPY E-VIDEOS}

https://eref.thieme.de/e-videos

口回 Endoscopy E-Videos is an open access online section, 回梠: reporting on interesting cases and new techniques in gastroenterological endoscopy. All papers include a high quality video and all contributions are freely accessible online. Processing charges apply (currently EUR 375), discounts and wavers acc. to HINARI are available.

This section has its own submission website at

https://mc.manuscriptcentral.com/e-videos 